\title{
Peran Program Tahfiz al-Quran Dalam Meningkatkan Perilaku Belajar terhadap Anak-anak dan Remaja
}

\author{
Wagiman Manik ${ }^{1}$, Ibnu Fisabilillah ${ }^{2}$ \\ ${ }^{1}$ Sekolah Tinggi Agama Islam As-Sunnah, Deli Serdang \\ 2. Sekolah Tinggi Agama Islam As-Sunnah, Deli Serdang \\ wagimanmanik85@gmail.com
}

\begin{abstract}
ملخص
الأخلاق الكريمة هي من أعظم العبادة، ولها فوائد كثيرة منها حسن الخلق يرتقي بصاحبه إلى الدرجات العالية من الإيمان، و بعث مله الله نبيه محمدا صلى الله عليه وسلم للدعوة إلى الأخلاق الصالحة، وأقرب الناس منزلة من رسول الله صلى الله عليه وسلم، وغير مئه ذلك من فوائد الأخلاق الكريمة. ومن طريقة كسب الأخلاق الصالحة بحفظ القرآن، لأن القرآن سيطهر ما في القب ويؤثر في الجوارح. وهذا الذي سيُطبَّقُه في البرنامج التدريب الميداني بمنطقة سولوك سومترى الغربية. لأن المشكلة هناك كثير من الأطفال أو الأولاد ليس لهم حسن الخحلق، بل يقعون في الجريمة والمعاصي، ومن أسباب ذلك قلة اهتمام آبائهم بتربية أبنائهم وقلة اهتمامهم بالقرآن، لذلك ستنفذ حلقة حفظ القرآن. فهذا البرنامج يفيدهم وتحسن أخلاقهم بعد أن يشتركوا في حلقة حفظ القرآن .والطريقة المستخدمة في خدمة المجتمع تستخدم أسلوب البحث التشاركي حيث يقوم الباحث بثلاث مراحل وهي التخطيط وتنفيذ وتقييم.

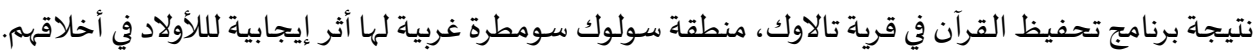

الكلمات الرئيسية : الأخلاق الكريمة ؛ منطقة سولوك ؛ حفظ القرآن
\end{abstract}

\begin{abstract}
Abstrak
Akhlak yang mulia merupakan salah satu ibadah yang paling agung, dan memiliki banyak manfaat, diantaranya akhlak yang baik akan mengangkat pemiliknya ke tingkat keimanan yang tinggi. Salah satu cara untuk memperoleh akhlak yang baik adalah dengan menghafal Al-Qur'an, karena Al-Qur'an akan mensucikan apa yang ada di hati dan mempengaruhi jiwa. Hal ini akan diterapkan dalam program pelatihan lapangan di kabubaten Solok Sumatera barat. Permasalahan yang banyak terjadi disini banyak anak-anak tidak memiliki akhlak yang baik dan bahkan melakukan perbuatan tercela, salah satu penyebabnya adalah kurangnya perhatian orang tua dalam dalam menididik anaknya dan kurangnya perhatian mereka untuk mengajarkan AlQur'an, oleh karena itu akan dilakasanakan program hafalan Qur'an dan diharapkan Program ini bermanfaat bagi mereka dan meningkatkan moral mereka setelah mereka mengikutiprogram tahfiz al-Qur'an. Dan metode yang digunakan dalam pengabdian masyarakat ini menggunakan metode partisipatori action research dimana penulismelakukan tiga tahap yaitu perencanaan, aksi dan evaluasi di lapangan. Hasil dari kegiatan tahfidz ini berdampak positif bagi anak-anak terhadap moral mereka.
\end{abstract}

Kata Kunci: Akhlak Karimah; Kabupaten Solok; Tahfiz Qur'an

Article Info

Article History:

Recived: 28/09/2021. Accepted: 11/12/2021. Publish: 16/12/2021. 


\section{Pendahuluan}

Akhlak yang mulia merupakan ciri khas seorang muslim karena terdapat banyak anjuran dalam Alquran dan hadis agar kita menjadi orang yang berakhlak mulia, dan ini sudah dicontohkan oleh nabi Muhammad Shallallâhu alaibi wa sallam sebagaimana yang kita ketahui dalam kisah perjalanan hidup beliau, nabi Muhammad Shallallâhu alaibi wa sallam diakui oleh semua orang sebagai manusia yang terbaik akhlaknya, diakui oleh para sahabatnya bahkan juga diakui oleh orang yang menentang dakwahnya, betapa banyak orang yang masuk agama Islam disebabkan oleh akhak beliau yang mulia, kemudia Rasulullah Shallallâhu 'alaibi wa sallam juga diutus menjadi nabi untuk menyempurnakan akhlak yang mulia.

Kata akhlak berasal dari bahasa Arab yaitu khuluqun yang berarti perangai, tabiat, adat atau khalqun yang berarti kejadian, buatan, ciptaan. Jadi akhlak itu berarti perangai, adat, tabiat atau sistem perilaku yang dibuat. Namun yanng sudah dipahami di Indonesia kata akhlak sudah mengandung konotasi baik, jadi orang yang berakhlak berarti orang yang berbudi baik atau berakhlak mulia. ${ }^{1}$

Dengan terselenggaranya kegitan KKL secara mandiri mahasiswa STAI As-Sunnah di Desa Talaok, Kecamatan Hiliran Gumanti, Kabupaten Solok, Provinsi Sumatera Barat, maka setelah mempelajari dan melihat keadaan yang ada ternyata banyak fenomena yang terjadi khususnya yang akan dibahas adalah rusaknya akhlak anak anak karena jauhnya mereka dari Alquran, maka mengadakan kegiatan tahfiz Alquran untuk anak anak, guna untuk mengatasi masalah yang sedang terjadi di desa Talaok, kecamatan hiliran gumanti, kabupaten solok, provinsi sumatera barat.

Seiring dengan berkembangnya zaman dan teknologi semakin maju perilaku anak anak memiliki pergeseran kearah yang tidak baik, betapa banyak anak anak sekarang yang sudah terpengaruh dengan pergaulan bebas, menghabiskan waktu mereka untuk hal hal yang tidak bermanfaat, tidak menghormati guru, melewan atau durhaka kepada orang tua, bahkan ada yang melakukan tindakan kriminal, itu semua berasal dari buruknya akhlak anak anak karena tidak adanya penanaman akhlak yang mulia Penanaman akhlak yang mulia memiliki banyak tujuan, diantaranya yaitu agar mendapatkan ridha Allah Subhānahu wataāāa, kemudian agar generasi muda yang akan meneruskan perjuangan bangsa memiliki kepribadian yang mulia serta memiliki bekal yang cukup untuk menjalani kehidupan dengan keadaan zaman yang semakin terbuka dan dinamis ini, sehingga tidak mudah terpengaruh oleh perkembangan zaman. Keadaan zaman tersebut sedikit banyak telah merubah cara hidup manusia, yang mana semua perkembangan tidak semuanya baik untuk diikuti karena dampak negatifnya bagi diri bangsa dan negara. Sebagaimana yang kita ketahui sekarang dengan mudahnya seseorang memperoleh informasi dari berbagai media sehingga peluang untuk mengikuti gaya hidup sangatlah besar. Akan tetapi, perkembangan tersebut tidak hanya berdampak positif saja bagi masyarakat tetapi juga memberi dampak negatif pula terutama bagi generasi muda bangsa. Akhlak yang mulia yang sudah mengakar dalam jiwa seseorang akan menjadi benteng baginya sehingga tidak mudah dikendalikan oleh nafsu dan keinginan yang buruk yang hanya mementingkan kesenangan di dunia dan mengabaikan pertanggungajawaban di akhirat, hanya hanya mementingkan kehidupan pribadi tanpa memikirkan keadaan bersama. Salah satu cara untuk mengubah akhlak anak anak menjadi

\footnotetext{
${ }^{1}$ M. Hasan, membentuk, pribadi muslim, (yogyakarta : pustaka nabawi, 2002), h. 1
} 
anak anak yang berakhlak mulia yaitu dengan menghafal Alquran. Menghafal Alquran atau yang dikenal dengan tahfidz Alquran merupakan gabungan dari dua kata yaitu kata tahfidz dan Alquran, kata tahfidz berasal dari bahasa arab yang merupakan masdar dari kata baffadza yang artinya menghafal, menghafal berasal kata hafal yang dalam bahasa arab disebut hafidza yahfadzu hifdzan yang merupakan lawan dari kata luupa, yaitu selalu ingat dan sedikit lupa. $^{2}$

Kemudian Abdul Aziz mengemukakan bahwa menghafal adalah "proses mengulang sesuatu baik dengan membaca atau mendengar" pekerjaan apapun jika selalu diulang, akan menjadi hafal. ${ }^{3}$

Sedangkan Alquran secara bahasa berarti bacaan. ${ }^{4}$ Salah satu kekhususan Alquran dari kitab kitab yang lain ialah Alquran dalam penjagaanya langsung dijaga oleh Allah Subhānahu wata'ālà sebagai mana firman Allah Subhạnahu watáālā

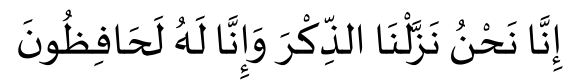

\section{"Sesunggubnya kamilah yang menurunkan Alquran, dan pasti kami pula yang memeliharanya"}

Berbeda dengan kitab kitab terdahulu yang penjagaannya diserahkan kepada orang orang sholeh diantara mereka karena kitab kitab terdahulu diperuntukkan untuk satu waktu saja sedangkan al quran berlaku sampai hari kiamat kelak. ${ }^{6}$ Maka salah satu bentuk penjagaan Allah Subhānahu watáăà terhadap Alquran adalah banyaknya para penghafal Alquran dari semua kalangan; orang dewasa, anak anak, laki laki dan perempuan.

Dalam menghafal al quran ada beberapa hal yang harus diperhatikan dan diterapkan, pertama harus mengikhlaskan niat karena Allah subhanu wata'ala, ini adalah pondasi utama dalam melakukan sebuah ibadah yang termasuk didalamnya menghafal Alquran. ${ }^{7}$ karena apapun perbuatan baik yang kita lakukan tanpa didasari dengan keikhlasan tidak akan tercatat sebagai suatu amal kebaikan disisi Allah Subhānahu watáālā. Kedua mengetahui keutamaan keutamaan seraong yang hafal Alquran; sudah tidak diragukan lagi bahwa menghafal Alquran merupakan sebuah keutamaan yang besar, sangat banyak hadis hadis nabi yang mengabarkan bahwa orang yang hafal Alquran mendapatkan banyak kemulian, salah satunya dia akan memasangkan mahkota untuk kedua orang tuanya kelak di akhirat. ${ }^{8}$ Ketiga, sebelum mengafal Alquran hendaknya memulai dengan memperbaiki bacaan Alquran; dalam menghafal harus dihafal sebagaimana mesti bacaan Alquran yang benar maka sebaiknya memperbaiki bacaan terlebih dahulu sebelum mulai menghafal Alquran atau yang disebut dengan tabsin. Tahsin adalah pembenaran harakat, makharijul huruf, dan kriteria setiap huruf yang membedakan satu sama lain, pembelajaran tahsin ini harus melibatkan orang lain yaitu seorang guru yang akan memperbaiki bacaan. ${ }^{9}$ Ini sesuai dengan firman Allah Subhānahu watáălä:

${ }^{2}$ Mahmud Yunus, kamus bahasa arab-indonesia, (Jakarta: Hidakarya Agung, 1990), h. 105

3 Abdul Aziz Abdul Rauf, kiat sukes menjadi hafidz qur'an da'iyah, (Bandung : pt syamil cipta media, 2004), cet. 4, h. 49

${ }^{4}$ Nasrudin Razak, dienul islam (Bandung: PT. Alma’arif, 1997), h. 86

${ }^{5}$ Q.S al hijr : 9

${ }^{6}$ Manna' Khalil Qattan, studi ilmu ilmu Alquran, (Surabaya: Halim Jaya, 2012), h. 13

7 Sa'adullah, 9 Cara Praktis Menghafal Alquran, (Jakarta: Gema Insani, 2008), h. 29

${ }^{8}$ Ibid., h. 23

${ }^{9}$ Yahya Abdurrazaq, Metode Praktis Menghafal Alquran, (Jakarta: Pustaka Azzam, 2004), h. 78 


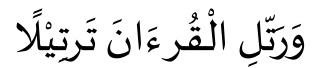

\section{"...dan bacalah Alquran itu dengan perlahan-lahan."10}

Keempat, mempunyai kemamuan yang kuat, ketika ingin melakukan sebuah pekerjaan diharuskan memiliki kemauan dan tekad yang kuat, terlebih lagi ketika ingin menghafal Alquran maka kemauan yang kuat harus diperlukan agar cita cita menjadi penghafal Alquran tercapai dan bisa melewati berbagai rintangan dalam menghafal Alquran. Keteguhan dan kesabaran merupakan faktor ayng sangat penting bagi orang yang sedang dalam proses menghafal Alquran. ${ }^{11}$ kelima, disiplin dan istiqamah dalam menghafal Alquran, kedisiplinan tidak hanya dibutuhkan dalam pekerjaan umum saja namun juga diperlukan dalam menghafal Alquran bahkan tidak akan tercapai cita cita mengahafal Alquran tanpa sebuah kedisiplinan, seorang yang ingin menghafal Alquran harus disiplin dalam mengulang dan menambah hafalan Alquran, harus gigih dalam memanfaatkan waktu luang dan meninggalkan kesibukan kesibukan yang tidak bermanfaat. ${ }^{12}$ yang ke-enam, banyak berdo'a kepada Allah Subhānahu wata älā agar diberi kemudahan untuk menghafal, do'a adalah senjata bagi orang Islam agar Allah memberikan kemudahan, karena Allah maha mengabulkan do'a, juga Allah telah menjanjikan didalam Alquran bahwa Allah akan memberikan kemudahan untuk menghafal Alquran. Ketujuh, membuat target hafalan, ini sangat membantu dalam proses menghafal Alquran dan dalam mengulang hafalan Alquran, hendaklah seorang yang ingin menghafal Alquran membuat target yang diinginkan sesuai kemampuan yang dimiliki dan membuat target untuk mengulang hafalan Alquran sesuai dengan kondisi dan waktu yang ada. ${ }^{13}$

Agar bisa menghafal Alquran ada beberapa metode yang bisa dipakai untuk menghafal Alquran untuk mencari alternatif terbaik dalam menghafal Alquran, dan bisa memberikan bantuan kepada para penghafal agar bisa menghafal Alquran dengan cepat dan mengurangi kesulitan dalam menghafal Alquran. Metode itu diantaranya: (1) metode wahdah, yaitu Yaitu menghafal satu persatu terhadap ayat-ayat yang hendak dihafalnya. Untuk mencapai hafalan awal, setiap ayat bisa dibaca sebanyak sepuluh kali, atau dua puluh kali atau lebih sehingga proses ini mampu membentuk pola dalam bayangannya. Dengan demikian penghafal akan mampu mengkondisikan ayat-ayat yang dihafalkannya bukan saja dalam bayangannya, akan tetapi hingga benar-benar membentuk gerak refleks pada lisannya. Setelah benar- benar hafal barulah dilanjutkan pada ayat-ayat berikutnya dengan cara yang sama, demikian seterusnya hingga mencapai satu halaman Alquran, kemudian dilanjutkan dengan hafalan selanjutnya.(2) metode sima'i atau mendengarkan yaitu mendengarkan sesuatu bacaan untuk dihafalkannya, metode ini sangat efektif untuk anak anak yang belum bisa membaca Alquran. Kemudian dalam tulisan ini akan dibahas bagaimana anak anak di desa Talaok, kecamatan Hiliran Gumanti, kabupaten Solok, provinsi Sumatera Barat dalam mempraktekkan metode menghafal Alquran dan bagaimana dampak kegiatan tahfiz tersebut dalam menanamkan akhlak yang mulia pada anak anak di desa tersebut.

Dugaan yang menjadi faktor dominan adalah kurangnya perhatian orang tua terhadap anak anak sehingga mereka melalaikan pendidikan mereka yang seharus anak anak mendapatkan pengajaran dan pembelajaran yang bagus, terkhusus untuk menghafal

\footnotetext{
${ }^{10}$ QS. Al-Muzzammil : 4

${ }^{11}$ Ahsin Wijaya Hafizh, Bimbingan Praktis Menghafal Alquran (Jakarta : Amzah, 2008), h. 53

${ }^{12}$ Ibid., h. 50

${ }^{13}$ Yahya abdurrazaq, metode praktis menghafal Alquran, h. 118
} 
Alquran masa anak- anak adalah masa yang paling bagus dan baik untuk menghafal Alquran sudah banyak bukti dari para ulama ulama terdahulu bahwa mereka menghafal Alquran pada masa anak anak. Dugaan selanjutnya tidak adanya dari pihak pemerintahan setempet atau orang orang yang berhak untuk mengadakan kegiatan tahfizh Alquran, sehingga anak anak tidak begitu mengenal hafalan Alquran, kemudian kurangnya motivasi anak anak untuk menghafal Alquran, dan juga tidak ada contoh dari teman teman dan saudarnya untuk menghafal Alquran sehingga waktu mereka banyak dihabiskan untuk hal hal yang tidak bermanfaat, tersibukkan dengan bermain game online dan sebagainya, yang itu semua menjauhkan mereka dari Alquran, menjauhkan mereka dari membaca Alquran, menjauhkan mereka dari menghafal Alquran, yang pada akhirnya berdampak buruk pada akhlak.

Maka kegiatan yang dilakukan sangat efektif untuk menanggulangi permasalahan permasalahan yang mereka hadapi yaitu dengan mengadakan kagiatan tahfizh Alquran. berakhlak mulia dengan menghafal Alquran, karena untuk mencapai akhlak yang baik harus dilakukan berbagai usaha. Manusia berkarakter tentu tidak bisa lahir dan tercipta dengan sendirinya. Proses pembentukan karakter tidak bisa dilakukan secara parsial. melainkan harus meliputi berbagai hal, integrative antara kehidupan jasmani dan rohani, holistic yang meliputi berbagai potensi manusia. ${ }^{14}$

Adapun Tujuan dari KKL ini adalah (1 )mengetahui keadaan dan kenyataan yang terjadi dimasyarakat, (2) Mengidentifikasi berbagai persoalan dan tantangan di dunia kerja, (3) Memahami penerapan ilmu pengetahuan dan teknologi yang dipelajari di perkuliahan pada berbagai aspek dunia kerja.

Manfaat langsung yang dapat dirasakan oleh mahasiswa, program studi, fakultas dan institusi adalah (1) Meningkatnya wawasan mahasiswa dalam dunia kerja sesuai bidang ilmu, (2) Memberikan gambaran kepasda mahasiswa tentang hubungan antara teori dan penerapanya serta faktor-faktor yang mempengaruhinya, (3) Memberikan bekal dan pengenalan kepada mahasiswa tentang dunia kerja yang sesuai dengan bidang ilmu. Tulisan ini merupakan kajian deskriptif dengan data kualitatif di Desa Talaok, Kecamatan Hiliran Gumanti, Kabupaten Solok, Provinsi Sumatera Barat pada tahun 1442 H, 2021 M

Tulisan ini merupakan kajian deskriptif yang mana mahasiswa riset aksi melihat apa sumber masalah yang terjadi pada kegitan KKL secara mandiri mahasiswa STAI As-Sunnah di Desa Talaok, Kecamatan Hiliran Gumanti, Kabupaten Solok, Provinsi Sumatera Barat,. Adapun metode yang digunakan dalam kegiatan riset aksi ini yaitu Participatory Action Reasearch. Participatory Action Reasearch atau Kegiatan partisipasi dalam penelitian menurut Kemmis dan McTaggert merupakan penelitian tindakan kegiatan sebagai hasil dari proses penelitian, yaitu penelitian yang diawali dengan merencanakan, melakukan tindakan atau aksi, dan evaluasi dari hasil tindakan. Proses penelitian tersebut merupakan tindakan dalam memahami dan mengubah praktik sosial serta melibatkan praktisi pada tahap-tahap penelitian ${ }^{15}$.

PAR bersifat transformative dan memberdayakan komunitas yang ada di Desa Talaok, Kecamatan Hiliran Gumanti, Kabupaten Solok, Provinsi Sumatera Barat, sehingga menghasilkan sebuah program Tahfiz al-Quran, yaitu program yang terstruktur dalam pelaksanaan menghafal

al-Quran.

${ }^{14}$ Sjarkawi, Pembentukan Kepribadian Anak; Peran Moral, Intelektual, Emosional, dan Sosial sebagai Wujud Integritas Membangun Jati diri, (Jakarta: Bumi Aksara 2006), h. 45

15 Kemmis, Stephen, Robbin McTaggart, and Rhonda Nixon. THE ACTION RESEARCH PLANNER Doing Critical Participatory Action Research. Edited by Stephen Kemmis and Robbin McTaggart. Third edit. Victoria: Deaken University, 1997. 


\section{Hasil dan Pembahasan}

Sebagai seorang muslim dalam menjalani kehidupannya tidak akan terlepas dari tuntunan Alquran, kerana Allah Subhāanahu watáălà telah menjadikan Alquran sebagai kitab petunjuk yang didalamnya terdapat semua solusi dari permasalahan kehidupan. Maka sudah selayaknya seorang muslim untuk selalu berinteraksi dengan Alquran, baik dengan cara membaca Alquran, memahami isi kandungan Alquran, menghafal Alquran dan berbagai kegiatan lainnya. Kerana Alquran merupakan kitab yang mulia maka apapun yang melekat dengan Alquran menjadi mulia, seperti bulan ramadhan menjadi bulan yang sangat agung kerana pada bulan tersebut diturunkannya Alquran, malam lailatul qadar menjadi malam yang terbaik sepanjang masa karena pada malam tersebut diturunkannya Alquran, dan juga salah satu sebab nabi muhammad Shallallâhu 'alaibi wa sallam menjadi orang yang paling mulia karena kepada beliau diturunkannya Alquran. Maka ketika kita ingin menjadi orang yang mulia dan menjadi orang yang berakhlak yang mulia harus banyak berinteraksi dengan Alquran, yang salah satunya dengan menghafal Alquran.

Kegiatan tahfizh Alquran diadakan di desa desa Talaok, kecamatan hiliran gumanti, kabupaten solok, provinsi sumatera barat, tepatnya di mushalla al Hijrah. mengadakannya setiap hari setelah shalat ashar sampai jam 17.30 sore hari, jumlah total peserta kegiatan tahfizh 24 orang, ini sudah sangat banyak berdasarkan jumlah penduduk yang ada di desa ini. Adapaun kegiatan ini melibatkan berbagai pihak, diantaranya pengurus mushalla al Hijrah yang menfasilitasi kegiatan tahfizh Alquran dengan mengizinkan memakai berbagai fasilitas yang ada di mushalla, kemudian orang tua peserta kegiatan tahfizh Alquran yang mengizinkan anak anaknya mengikuti kegiatan ini dan menfasilitasinya mulai dari Alquran, meja dan mengantar anak anaknya untuk mengikuti kegiatan tahfiz, kemudian masyarakat secara umum yang secara tidak langsung mengawasi kegiatan ini.

Sebelum mengawali pendaftaran tahfizh Alquran diberikan motivasi motivasi kepada anak anak dan masyrakat agar anak anaknya dididik untuk menghafal Alquran, dan ternyata kagiatan ini mendapat respon yang baik dari anak anak dan orang tua untuk mengikuti kegiatan tahfizh Alquran.

Dalam kegiatan tahfizh di mushallah al Hijrah diterapkan pada peserta berbagai metode dalam menghafal Alquran, yang pertama metode wahdab Yaitu menghafal satu persatu terhadap ayat-ayat yang hendak dihafalnya. ${ }^{16}$ Setelah peserta tahfizh diberikan target hafalan yang akan dihafal dalam satu pertemuan tersebut menyuruh mereka untuk membacanya satu ayat pertama dengan berulang kali sekitar dua puluh sampai empat puluh kali bahkan lebih sehingga proses ini mampu membentuk pola dalam bayangannya hingga benar benar membentuk gerak refleks pada lisannya, memilih seperti ini karena anak anak dalam menghafal Alquran belum bisa memahami isi Alquran sebagai pembantu mereka mengingat hafalan Alquran, adapun kalau orang dewasa mereka bisa mempelajari isi Alquran dengan mengkaji tafsirnya sehingga membantu mereka untuk mengingat hafalan Alquran, namun tingkat anak anak belum bisa menerapkan hal tersebut. Setelah mereka mengulang ulang ayat pertama tersebut hingga hafal baru bisa melanjutkan hafalan pada ayat selanjutnya dengan melakukan cara yang sama.

${ }^{16}$ Iqlima Zahari, Pembelajaran Tabfizh Alquran Pesantren Nurul Huda Mergosono Malang, 01, (juni, 2017), h 
Setelah peserta meyelasaikan target hafalan untuk satu pertemuan tersebut peserta diarahkan duduk dengan temannya dua orang setiap mereka saling menyetorkan hafalan mereka kepada temannya dan temannya memperbaiki kesalahan kesalahan hafalannya, Setelah itu baru menyetorkan hafalan kepada guru. Kemudian kami juga mengadakan ujian setiap tiga hari terhadap hafalan yang telah mereka selesaikan.

Adapun yang kedua yaitu metode sima'i atau mendengarkan, yaitu mendengarkan sesuatu bacaan untuk dihafalkannya, ${ }^{17}$ metode ini sangat efektif untuk anak anak yang belum bisa membaca Alquran. Perserta yang mengikuti kegiatan tahfizh di mushalla al Hijrah tidak semuanya lancar membaca Alquran, akan tetapi ada anak anak yang belum lancar membaca Alquran dengan benar, maka diperlukan metode ini untuk memperdengarkan kepada mereka ayat ayat yang akan mereka hafal, untuk memperdengarkan ayat ayat yang akan mereka hafal ada dua cara yaitu (1) memperdengarkan secara langsung, yaitu seorang guru guru membacakan secara berulang ulang yang kemudian peserta mengikutinya sesuai yang di bacakan guru, (2) memperdengarkan secara tidak langsung, seperti memperdengarkan ayat yang ingin dihafal melalui hp, speaker dan lain sebagainya.

Kegiatan ini sangat berdampak positif bagi orang tua dan anak anak di desa desa Talaok, kecamatan hiliran gumanti, kabupaten solok, provinsi sumatera barat, tepatnya di mushalla al Hijrah. Kegiatan tahfizh ini dengan izin Allah Subhänahu watáäà berhasil mengubah akhlak anak anak di desa talaok menjadi anak anak yang berakhlak mulia, orang tua peserta tahfizh sering melihat anak anaknya menghafal Alquran dirumah, yang awalnya mereka mengisi hari hari mereka dengan hal hal yang tidak bermanfaat seperti bermain game online, begadang dengan teman sebaya, namun sekarang mereka sudah mulai mengisi waktu mereka dengan hal yang bermanfaat, yang sebelumnya mereka sering melawan kepada orang tua sekarang sudah berkurang karena seorang yang ingin menghafal Alquran harus meninggalkan perbuatan dosa apalagi dosa besar.

Masyarakat juga berterima kasih karena telah diadakannya kegiatan tahfizh Alquran ini, kerana sebelumnya tidak ada guru yang ingin mengajarkan anak anaknya untuk menghafal Alquran, sedangkan mereka sibuk dengan pekerjaan masing masing sehingga pendidikan anak anak mereka sering terlalaikan.

Selanjutnya mahasiswa kegiatan Riset Aksi STAI As-sunnah melakukan tahap refleksi dan evaluasi, dimana hasilnya cukup signifikan. Terutama pada orang tua, yang pada awalnya kurang peduli dengan kemampuan baca dan kualitas bacaan alquran anak-anak, setelah pelaksanaan kegiatan riset aksi kepedulian para orang tua meningkat. Terlihat dari antusias mererka dalam mendukung dan mengikuti seluruh alur kegitan yang dilaksanakan oleh mahasiswa STAI As-sunnah. Tidak sampai disitu, bahkan banyak diantaranya yang menyumbangkan materi sebagai upaya mendukung kegitatan yang dilaksanakan. ${ }^{18}$

\section{Penutup}

Orang Islam harus terlihat dariya akhlak yang baik, al-Quran dan hadits memerintahkan untuk berakhlak yang baik atau mulia. Salah satu cara untuk mencapainya adalah dengan menghafal Alquran, dan ini yang telah kami praktekkan di desa Talaok, kecamatan hiliran gumanti, kabupaten solok, provinsi sumatera barat. Kami menerapkan

17 Ibid., h. 58

18 Pain, Rachel, Geoff Whitman, and David Milledge. "Participatory Action Research Toolkit: An Introduction to Using PAR as an Approach to Learning, Research and Action." Building Adaptive Strategies for Environmental Change with Land Use Managers (2011): 1-8. 
dua metode menghafal Alquran yaitu dengan metode wahdah dan sima'i, anak anak peserta tahfizh mengikut kegiatan dengan baik sehingga berhasil menghafal sesuai yang ditargetkan dan itu semua dengan izin Allah berhasil mengubah akhlak mereka menjadi lebih baik.

Karena dengan banyak berinteraksi dengan Alquran akan memperbaiki kehidupan seorang dan juga karena dalam menghafal Alquran membutuhkan waktu yang banyak untuk menambah da mengulang hafalan, yang biasanya mereka mengisi waktu untuk hal hal yang tidak bermanfaat bahkan perbuatan dosa sekarang mereka isi dengan menghafal Alquran. Saran kami agar para orang tua dan kepada orang orang yang berwewenang mengatur pendidikan agar lebih memperhatikan lagi pendidikan anak anak terutama pendidikan mereka terhadap Alquran, karena di usia anak anak adalah masa terbaik untuk menghafal Alquran, sehingga mereka memiliki hubungan yang kuat dengan Alquran sebagai bekal mereka menghadapi zaman yang sudah maju agar mereka selalu berakhlak yang mulia.

\section{Bibliografi}

Abdul Aziz Abdul Rauf, kiat sukses menjadi hafidz qur'an da'iyah, Bandung : pt syamil cipta media, 2004

Abdurrazaq Yahya, Metode Praktis Menghafal Alquran, Jakarta: Pustaka Azzam, 2004.

Hafizh Ahsin Wijaya, Bimbingan Praktis Menghafal Alquran Jakarta : Amzah, 2008.

Hasan M., membentuk pribadi muslim, yogyakarta : pustaka nabawi, 2002 .

Iqlima Zahari, Pembelajaran Tabfį̌h Alquran Pesantren Nurul Huda Mergosono Malang, 01, (juni, 2017).

Qattan Manna' Khalil, studi ilmu ilmu Alquran, Surabaya: Halim Jaya, 2012.

Razak Nasrudin, dienul islam Bandung: PT. Alma'arif, 1997.

Sa'adullah, 9 Cara Praktis Menghafal Alquran, Jakarta: Gema Insani, 2008.

Sjarkawi, Pembentukan Kepribadian Anak; Peran Moral, Intelektual, Emosional, dan Sosial sebagai Wujud Integritas Membangun Jati diri, Jakarta: Bumi Aksara 2006.

Yunus Mahmud, kamus bahasa arab-indonesia, Jakarta: Hidakarya Agung, 1990.

Kemmis, Stephen, Robbin McTaggart, and Rhonda Nixon. THE ACTION RESEARCH PLANNER Doing Critical Participatory Action Research. Edited by Stephen Kemmis and Robbin McTaggart. Third edit. Victoria: Deaken University,

Pain, Rachel, Geoff Whitman, and David Milledge. "Participatory Action Research Toolkit: An Introduction to Using PAR as an Approach to Learning, Research and Action." Building Adaptive Strategies for Environmental Change with Land Use Managers (2011):

$1-8$. https://www.dur.ac.uk/resources/beacon/PARtoolkit.pdf\%5Cnhttps://www.dur.ac. uk/beacon/socialjustice/publications/participatory/\%0Ahttp://communitylearningpa rtnership.org/wp-content/uploads/2017/01/PARtoolkit.pdf. 